East African Medical Journal Vol. 81 No. 6 June 2004

COMMUNITY SATISFACTION WITH THE QUALITY OF MATERNAL AND CHILD HEALTH SERVICES IN SOUTHEAST NIGERIA

B.S.C. Uzochukwu, MBBS, MPH, FWACP, Lecturer/Consultant, Department of Community Medicine, O. E. Onwujekwe, MBBS, MSC, PhD., Lecturer, Health

Policy Research Unit, Department of Pharmacology and Therapeutics, College of Medicine, University of Nigeria, Enugu-Campus, Nigeria and C. O. Akpala, MBBS, MPH, FWACP, Director, National Primary Health Care Development Agency, Zone A Headquarters, Enugu, Nigeria.

Request for reprints to: Dr. B.S.C. Uzochukwu, Department of Community Medicine, College of Medicine, University of Nigeria, Enugu, P.O. Box 3295, Enugu, Nigeria

\title{
COMMUNITY SATISFACTION WITH THE QUALITY OF MATERNAL AND CHILD HEALTH SERVICES IN SOUTHEAST NIGERIA
}

\author{
B. S. C. UZOCHUKWU, O. E. ONWUJEKWE and C. O. AKPALA
}

\begin{abstract}
Objectives: To assess community perception, practices and satisfaction with the quality of maternal and child health services and the willingness and ability to pay for the services, after the introduction of the Bamako initiative programme.

Design: A cross sectional study using pre-tested questionnaire and focus group discussions was undertaken in May 1999. Variables explored were rating of quality of services, level of satisfaction with the services and willingness to pay for quality improvements as well as ability to pay for services.

Setting: Oji-river local government area of Enugu State, Nigeria.

Subjects: A random sample of $\mathbf{4 0 5}$ households from a sample frame of primary health care house numbers and another purposive sample of women and males were involved. Results: Most respondents $\mathbf{( 9 0 . 6 \% )}$ rated the services to be at least good. Another $95.9 \%$, $\mathbf{9 4 . 3 \%}$ and $95.8 \%$ of the respondents were, satisfied with the childhood immunisation, antenatal care and childbirth services respectively. Eighty nine percent of respondents were willing to pay for health services if drugs were readily available, while $\mathbf{9 2 . 4 \%}$ would pay if there is overall improvement in quality. Majority of them were also able to pay for services. However, long waiting queues, providers' behaviours and lack of doctors militated against the utilisation of maternal and child health services.

Conclusion: Bamako initiative programme improved drug availability and physical appearance of the health centres thereby leading to high levels of consumer satisfaction and people are willing and able to pay for primary health care services if there are quality improvements, as the Bamako initiative achieved. Continuous improvement of services, especially constant drug availability would motivate people to pay for services.
\end{abstract}

\section{INTRODUCTION}

Nigeria has one of the highest maternal and infant mortality rates in the world and this necessitated the greater attention given to maternal and child health (MCH) services in the country's Bamako initiative (BI) programme . $\mathrm{MCH}$ consumers who are often poor, are mostly women, their children and families are also at extraordinary risk of receiving poor or no health care(1). Nigeria's infant mortality rate is about 96 per thousand live births in rural areas against 75 per a thousand life births in urban areas and only $89 \%$ and $59 \%$ of pregnant women in urban and rural areas respectively sought pre-natal care(2). Many African countries started implementing comprehensive primary health care programmes after the BI was launched and introduced user fees to generate revenue for the health sector(3)

The quality of services provided in the health centres operating the BI scheme and how people perceive that quality would determine the level of utilisation of the $\mathrm{MCH}$ services. In recent years developing countries, influenced heavily by findings in developed countries, have become increasingly interested in assessing the quality of their health care. Quality of care can be measured at three levels: the policy level; the service delivery level; and the client /outcome level. Outcomes have received special emphasis as a measure of quality. Assessing outcomes has merit both as an indicator of the effectiveness of different interventions and as part of a monitoring system directed to improving quality of care as well as detecting its deterioration(4,5). Quality assessment studies usually measure one of three types of outcomes: medical outcomes, costs, and client satisfaction. For the last mentioned, clients are asked to assess not their own health status after receiving care but their satisfaction with the services delivered $(6,7)$. The Bruce - Jain framework, the central paradigm for quality of family planning, emphasizes the importance of client's perspective $(6,7)$. It defines quality in terms of six fundamental elements: Choice of method (service), technical competence, information given to clients, 
inter-personal relations, mechanisms to ensure followup and continuity, and an appropriate constellation of services. The importance of peoples' perception of quality was demonstrated by Akin and Hutchinson(10), who found that the ill and poor people by-passed free or subsidised services in facilities they perceived to be offering low quality services. It was thus hoped that the BI would increase the quality and peoples' perception of the quality of services in public facilities, together with the utilisation of $\mathrm{MCH}$ services, in order to improve the health of mothers and children.

Thus, perceived quality is one of the most important determinants of patient's choice of provider and willingness to pay(11). Some studies found that consumers' satisfaction with health care services in Africa was one of the most important factors determining the utilisation of services(10,12-15). Determinants of perceptions of quality of services found in Tanzania include; perceived time spent at the facility, availability of immunisations, availability of $\mathrm{MCH}$ services and the staff strength of the health facilities(16). There is no existing study on consumers' perceptions of quality and satisfaction with $\mathrm{MCH}$ services under the BI programme especially in Nigeria.

The main objective of the present study was to assess in detail the expectations of quality of care and the level of satisfaction of patients attending BI health centres in rural Nigeria and there ability and willingness to pay for health services. A better understanding of the determinants of client satisfaction should help policy- and decision-makers to implement the BI programme tailored to patients' needs as perceived by patients. According to Haddad et al(17), the success of strategies to revitalise primary health care services such as those advocated by the BI requires a response adapted to the expectations of the population, especially in terms of quality. Also the World Bank have advised developing countries to ensure that health services are client-oriented(18).

\section{MATERIALS AND METHODS}

The study was conducted in Oji River Local Government Area in Enugu State, Southeast Nigeria. The area started implementing the BI programme in 1993 and has 21 primary health centres implementing the programme. The area also has two government owned general hospitals and 10 privately owned hospitals. A simple random sample of 405 households was selected using the Primary health care (PHC) house numbering as the sample frame. These households were selected if there was a woman that either had a live delivery 12 months before the survey or had a child under 12 months old. Only one woman with the inclusion criteria per household was invited to participate in the study. Using a pre-tested interviewer-administered questionnaire, information was collected from the women. In addition, focus group discussions FGDs were held with purposive samples of women of childbearing age (15-49 years) and men respectively. A total of four FGDs (two for each sample group) were held with 9-10 members, each lasting for between 60 and 75 minutes.

The household survey, in addition to collecting their socio-economic and demographic data, probed where the women that were ill two weeks before the survey, sought treatment and where they went for their antenatal clinic, delivery and childhood immunization the last time they were pregnant and after delivering. The women who used the BI health centres were asked to rate the quality of services they obtained on a four point scale ranging from very good to very poor. Three attributes of quality were used namely availability of prescribed drugs, observed physical appearance of the facilities and providers' behaviours. For availability of prescribed drugs, those whose prescribed drugs were all available were asked to rate the quality to be very good, those with nearly all the drugs being available answered good, those with less than half of the prescribed drugs poor and those with none of the drugs being available were asked to rate it very poor. In the observed structural changes, complete renovation with equipment and clean surrounding was rated as very good, complete renovation but without accompanying equipment as good, partial renovation as poor and no renovation with dirty surroundings as very poor. For providers' behaviour, they were allowed to rank them themselves based on their perception. They were also asked whether they were satisfied with the childhood immunisation services, antenatal care and childbirth services; if they ever had problems in paying for health services and if cost ever prevented them from using health services. Only women that had used these services were instructed to state whether or not they were satisfied with the quality of services. Also the women who delivered at the health centre were asked to answer yes or no to the type of quality changes in the health centres that would motivate them to pay. Those who did not use the health centers were asked to state their reasons for non-use. The focus group discussions provided more in-depth understanding of the issues explored with the questionnaire. The discussion explored the peoples' perceptions of good quality of care, providers' behaviours, general satisfaction, effectiveness and accessibility of health centers and suggestions for improving the quality of the services.

Tabulations were used to analyse the survey data, while the notes from the FGDs were transcribed and content analysis employed. The discussions were categorised into different themes on the peoples' perceptions of the quality changes, their level of satisfaction, complaints and areas for improvement. The education and stated income per month was used to generate the socio-economic index of the respondents and were therefore classified into four quartiles with quartile four being the richest.

The study received ethical approval from the Ethical Committee, University of Nigeria Teaching Hospital, Enugu. The authors had no conflicting interest with the contents of this paper. However, Professor Akpala is currently the Director of the Southeast zone, National Primary Health Care Development Agency, Nigeria. 


\section{RESULTS}

Survey: The highest proportion of respondents interviewed (30.4\%) were aged between 26 - 30 years. $5.4 \%$ of the respondents had no formal education, 164 $(40.5 \%)$ completed primary education, $193(47.7 \%)$ completed secondary education while $26(6.4 \%)$ had post-secondary education. While $70.6 \%$ of the women were in SES 1, 20.8\%, 3.7\% and 4.9\%, were in SES 2,3 , and 4 respectively.

A total of 252 (62.2\%) of the respondents or their child were ill at least two weeks prior to the interview and treatment was sought for $228(90.5 \%)$ of the illnesses. A total of $106(46.7 \%)$ of the ill cases utilised the BI health centres. While $318(91.1 \%)$ of the respondents used the BI health centres for childhood immunisation services after their last delivery, 263(67.6\%) and 238 (58.8\%) utilised them for antenatal and delivery services respectively.

A majority of the respondents who used the BI health centres for curative services $(90.6 \%)$ rated the quality of services in the health centres based on the availability of prescribed drugs, observed physical changes and providers' behaviours as good or very good, $6.6 \%$ rated it as poor, $2.8 \%$ as very poor, the ratings being statistically significantly different $(\mathrm{p}<$ 0.05 ) (Table 1). Table 2 shows that $95.9 \%, 94.3 \%$ and $95.8 \%$ of the respondents who used the BI facility were, satisfied with the childhood immunisation, antenatal care and childbirth services respectively. There was no statistical difference $(p>0.05)$ in satisfaction between the various services. Table 3 shows that majority of those who used the services could afford to pay for all the services. However, more than $20 \%$ of them could not pay for child-birth and curative services. There was statistical difference in having problems in paying for the various services $(\mathrm{p}<0.05)$. However, there was no statistical difference in cost ever prevented them from paying $(p>0.05)$. The women who delivered at the health centre gave varying reasons that would motivate them to pay for care in the health centres (Table 4). Thus, $92.4 \%$ of them were willing to pay if there was continual improvement in the overall quality of care, $64.3 \%$ would if the cost is affordable, $89 \%$ if there are constant supply of drugs and $29.4 \%$ were unconditionally willing to pay respectively. There was statistically significant difference $(p<0.05)$ in the conditions they are willing to pay with more willing to pay for continual improvement in the overall quality and constant supply of drugs.

Table 1

Rating of quality of care in the health centres for curative services $(n=106)$

\begin{tabular}{llll}
\hline Rating & No. & $(\%)$ & p-value \\
\hline Very good & 16 & $(15.1)$ & \\
Good & 80 & $(75.5)$ & \\
Poor & 7 & $(6.6)$ & p \\
Very poor & 3 & $(2.8)$ & 0.05 \\
\hline
\end{tabular}

Table 2

Level of satisfaction with health services at the health centres

\begin{tabular}{llllllll}
\hline & \multicolumn{2}{l}{ Immunisation } & \multicolumn{2}{c}{ Antenatal care } & \multicolumn{2}{c}{ Childbirth services } & P-value \\
& No. & $(\%)$ & No. & $(\%)$ & No. & $(\%)$ & \\
\hline Yes & 305 & 95.9 & 248 & 94.3 & 228 & 95.8 & P.0.05 \\
No & 13 & 4.1 & 15 & 5.7 & 10 & 4.2 & 100 \\
\hline *Total & 318 & 100 & 263 & 100 & 238 & \multirow{2}{*}{100} \\
\hline
\end{tabular}

\footnotetext{
* Used the health centre for various services
} 
Table 3

Affordability of health services at the health centres

\begin{tabular}{|c|c|c|c|c|c|c|}
\hline \multirow[t]{2}{*}{ Service } & \multicolumn{3}{|c|}{ Problems in paying for services } & \multicolumn{3}{|c|}{ Cost ever prevented from using health services } \\
\hline & Yes $(\%)$ & No. $(\%)$ & Total $(\%)$ & Yes $(\%)$ & No. $(\%)$ & Total $(\%)$ \\
\hline Curative & $14(13.2)$ & $92(86.8)$ & $106(100)$ & $22(20.8)$ & $84(79.2)$ & $106(100)$ \\
\hline Immunization & $5(1.6)$ & $313(98.4)$ & $318(100)$ & $8(2.5)$ & $310(97.5)$ & $318(100)$ \\
\hline Ante-natal & $24(9.1)$ & $239(90.9)$ & $263(100)$ & $11(4.2)$ & $252(95.8)$ & $263(100)$ \\
\hline Child-birth & $66(27.7)$ & $172(72.3)$ & $238(100)$ & $54(22.7)$ & $184(77.3)$ & $238(100)$ \\
\hline $\mathrm{p}$ - value & $\mathrm{P}<0.05$ & & & $\mathrm{P}>0.05$ & & \\
\hline
\end{tabular}

Table 4

Willingness to pay for different quality improvements

\begin{tabular}{lccccc}
\hline & Unconditional & $\begin{array}{l}\text { Availability } \\
\text { of drugs } \\
\text { No. }(\%)\end{array}$ & Affordable cost & $\begin{array}{l}\text { Improved overall } \\
\text { quality of care } \\
\text { No. }(\%)\end{array}$ & P-value \\
\hline No. $(\%)$ & $70(29.4)$ & $212(89)$ & $153(64.3)$ & $220(92.4)$ & $18(7.6)$ \\
No & $168(70.6)$ & $26(11)$ & $85(35.7)$ & P<0.05 \\
\hline Total & $238(100)$ & $238(100)$ & $238(100)$ & $238(100)$ \\
\hline
\end{tabular}

* Delivered at the health centre

Table 5

Reasons for non-use of primary health-care centres' services

\begin{tabular}{lllll}
\hline Reason & $\begin{array}{l}\mathrm{N}=122 \\
\text { Curative }(\%)\end{array}$ & $\begin{array}{l}\mathrm{N}=31 \\
\mathrm{Immunisation} \mathrm{( \% )}\end{array}$ & $\begin{array}{l}\mathrm{N}=126 \\
\text { Antenatal (\%) }\end{array}$ & $\begin{array}{l}\mathrm{N}=167 \\
\text { Delivery }(\%)\end{array}$ \\
\hline & & & & 26.3 \\
Too far* & 3.8 & 33.3 & 34.9 & 7.1 \\
Cost of treatment & 6.8 & 6.6 & 9.5 & 29.3 \\
Poor staff attitude & 29.5 & 26.7 & 47.6 & 5.3 \\
No drugs* & 21.4 & 13.3 & 5.0 & 56.3 \\
Absence of doctor* & 89.7 & 80 & 84.1 & 7.2 \\
Long waiting hours & 4.2 & 13.3 & 7.9 & \\
\hline
\end{tabular}

$* \mathrm{p}<0.05$ (statistically significant)

For those who did not use the health centres (Table 5), the most important reasons for non-use are the absence of a doctor for all the services, poor staff attitude for all the services, distance for all services except curative, and lack of drugs for curative services. Very few gave cost and long waiting hours as a reason. For the various services, there was statistically significant difference $(\mathrm{p}<0.05)$ in distance, no drugs and no doctor being the reasons for non-use.

Focus group discussions: Majority of the FGD participants $51 \%$ were in SES 1, $18 \%$ in SES 2, 6\% in SES 3 and $25 \%$ in SES 4 . Their ages ranged between 25 and 72 years. There were a total of 20 females and 18 male participants. The participants felt that the availability of medicines in the health centres had improved since the BI programme was started. They also stated that the physical appearance of the health centres had improved because of the renovations, had curtains and were much cleaner. According to one woman, "It looks like someone's house and there are chairs now for people to sit-in while getting treatment". However, a lot of the participants complained that the disposition of the health workers were sometimes very unfriendly. Some of the participants agreed that health workers differed in character, with some being courteous while some were not. However, in the view of one of the women, "I think the attitude of our nurses is bad because they have no respect or mercy for a patient and they insult patients without been provoked". The participants offered some explanations why staff behaviour might be bad. Some participants felt that because the health centres were understaffed, the health workers easily became tired and irritable coupled with the fact that the patients sometimes cause the problem by arguing and jumping queues. However, the most common explanation was that the nature of the job itself 
was seen as contributing, such that nurses were used to illness and death and were now insensitive to sick people. According to one of the men, "Nothing touches their heart any more".

Most of the participants agreed that the health centres were geographically close to their homes. However, they complained about the long waiting times, even when the queues were not long. Some of them said that this happens more on the days when the health centres conduct $\mathrm{MCH}$ immunisations.

A negative change in the health centres that some of the participants pointed out was the introduction of payments as part of the BI programme. In this vein, a number of participants commented that it was now impossible to access the health centre and or receive health-care without adequate money. Most of the participants felt that the reduction in queues in the health centres was because many people could not afford the fees and so do not attend. The actual amount paid depends on the type of problem, the severity of the illness and whether you are a child or adult. The amount ranges from 100 to 1000 Naira. And as some of the participants put it, "The money is mainly for drugs whether it is Bamako drugs or nurse bought them out side". "But if it is a small illness they can mix 20 to 50 Naira drugs for you". The cost of treating malaria for example is about 100 Naira. For delivery, the fee is 700 Naira for a male child and 600 Naira for a female child. They pay 15 Naira for BCG vaccination and 20 Naira for the other vaccinations.

However, they are told the money they pay for immunization is for buying needles, and syringes. Most of the participants claimed that cost influences their choice of health services and as two participants commented "the private clinics and the mission hospitals are very expensive. The health centre is usually cheaper. If you don't have money to pay at the centres then you are not given any treatment. "Anyway it is better to charge or collect small amount because people don't very much like free drugs, thinking that such drugs given free will not work. However, some apparently richer discussants said that the cost of treatment in the health centre was affordable. As one participant said "One has to pay because nothing is free these days".

However, the people were selective on the quality improvements they would be willing to pay for. Most of them said that they would pay for syringes for the immunisation of their children (though they remarked the government had said that immunisation services were free of charge). As one woman said "I do not mind paying for needles and syringes because I do not want my children to have AIDS". When asked the amount of money they are willing to pay, most of the participants agreed to pay 10 to 15 Naira for the syringes. The constant availability of a wide-range of drugs for all the common health conditions was the primary issue most of the respondents felt would keep improving the quality of the health centres and their level of satisfaction with the services. The people would also like doctors to be posted to the health centres to manage complicated pregnancies, childbirth and childhood diseases in addition to other serious diseases in the villages. Also, the participants requested that efforts should be made to reduce the waiting time, together with increasing the number of staff in the health centres.

One quality improvement plan most of the participants wanted to be instituted were strategies that would improve the behaviour of the health workers. Areas for staff improvement mentioned were; the health workers should be punctual, they should stop unduly favouring their friends and relatives, they should give more advice to patients on how to properly take their medicines at home and they should become more friendly. As one woman stated, "we want nurses who are kind, who do not shout, are not harsh or rude and who would not treat us as animals".

\section{DISCUSSION}

In this study, perception of the quality of care based on availability of prescribed drugs and general satisfaction with services offered and willingness and ability to pay for services was assessed. The level of satisfaction with $\mathrm{MCH}$ services offered in health centres implementing the BI programme and perceived quality of care based on availability of prescribed drugs, observed physical condition of the facilities and providers' behaviours were high. This is good as "improved quality of services increases the likelihood of a facility being used"(10). The availability of appropriate medication at the first point of contact with the health care system is probably one of the most important components of the quality of primary health care, and therefore a primary determinant of utilization(19). There is need for caution in accepting the women's responses in the household survey in terms of the level of satisfaction and perceived quality because of the long period of recall. However, this was authenticated in the FGDs. Most of the respondents would also be willing to pay for services if the quality improvements were maintained. They were also, actually able to pay for services as shown by their being able to afford the cost of services despite the fact that most of the respondents are of the lower SES. This signalled that the BI could be sustainable. This is because people are usually willing to pay for services, if they perceive the service to be of good quality $(20,22)$. The household survey results were also collaborated with the FGDs results where clients reported that one of the main achievements of the BI programme was availability of drugs, first from BI and most recently Petroleum Trust Fund. These findings contrast with the findings of Msamanga et al(19) where $80 \%$ of patients in public health facilities could not get their prescribed drugs available. Kanji et al(23) also demonstrated that only 
$12 \%$ of clients obtained their prescribed drugs. However, our results are in agreement with the findings of Ahmed et al.(24) where they showed that about $89 \%$ of patients from BI health centers obtained their prescribed drugs. According to some reports, provision of health care is expected to respond directly to patients' preferences and demands(25) as medical treatment is enhanced by greater patient satisfaction(26). Consequently, patient satisfaction is undoubtedly a useful measure, and to the extent that it is based on patients' accurate assessments, it may provide a direct indicator of quality care.

Although, majority of them were able to pay, there are those who could not pay. A drawback with the BI programme was that user charges were introduced for some $\mathrm{MCH}$ activities like antenatal and childbirth services amongst others. Prices tend to deter utilisation(10). This could exclude the poor from accessing vital antenatal and childbirth services. This would potentially defeat one of the major aims of the $\mathrm{MCH}$ component of the $\mathrm{Bl}$ since many poor pregnant women, especially in the rural areas that already have very low utilisation rates for antenatal and childbirth services would keep being denied of essential services. The user fees would also cause delay or even not seeking care when the women or their children are ill. Thus, fee exemptions and subsidies should be an integral part of the BI programme as part of improving the quality of the delivery of $\mathrm{MCH}$ services.

Among reasons for non utilisation of health centre services which might be a reflection of the perception of quality of care for the non-users of health services, the absence of a doctor ranked highest for all services although there was statistical difference between the services with less respondents for delivery services. This might be a reflection of the fact that the people can use delivery services even if there were no doctors as this is still the domain of midwifes. Others are poor staff attitude and distance. More respondents are not using curative and immunisation services than ANC and delivery because of lack of drugs. Thus for them drugs are not an important consideration for use of ANC and delivery services. Financial reasons was not much of a problem. This seems to agree with the findings of Soucat et al.(27) and Egunjobi(28) who revealed that only $2 \%$ of cases in a study, had cost as an important consideration for of patient care in Oyo state, Nigeria.

Despite the high level of satisfaction by consumers, they had reservations about some of the aspects of services rendered. Some of these could be said to be unique to the BI programme while others are common characteristics of public health care facilities in Nigeria and most sub-Saharan African countries. The long waiting-times, shortage of health workers and the unfriendly dispositions they sometimes exhibit to patients are not unique to the BI programme. Speizer and Bollen(16) also found that shortage of health workers was perceived as an indicator of low quality of care. Additionally, Newman et al.(15) found that lack of satisfaction with outpatient care were due to long waiting times, lack of physical examinations and failure to receive prescribed medications.

\section{CONCLUSION}

All in all, the BI programme improved drug availability and physical appearance of the health centres thereby leading to high levels of consumer satisfaction. Although user charges were introduced for some $\mathrm{MCH}$ activities like antenatal and childbirth services amongst others in BI, cost was not a major deterrent to utilisation as postulated by Akin and Hutchinson(10), and therefore did not affect their perception of quality. However, lack of doctors and limited staffing which are a reflection of perceived technical quality of care, poor attitude of health workers and long waiting hours are powerful predictors of client satisfaction and non-use of the centres, and therefore threaten the success of the programme. Improving the services, especially ensuring constant drug availability would motivate the people to pay for services. Also, since the BI programme is geared towards a holistic improvement of quality of care, means of better motivation to the health workers should be developed and implemented. The curriculum for the training of health workers that would work in the health centres should include strategies for good public relations with the consumers.

Our study is restricted to the views of users and non-users of health services and did not include the views of the health providers. We could not also classify the perceptions of the respondents by how long a woman has used the health centers. These are limitations of the study and a better design could have been to classify their perceptions by length of use and to sought the views of the health centre workers so as to get the professional aspect of quality of care.

Nevertheless, the study has identified bottlenecks in the health service delivery system that need to be addressed in order to improve the quality of government health facilities especially those operating the BI programme. It also forms the basis for assessing community reactions to $\mathrm{BI}$ and changing responses to the programme over time. This will lead to better management of health problems and to fewer unsatisfied patients as well as encouraging the non-users to use the BI centres. We did not also look at the willingness of the consumers to pay for health services in details and have used affordability as a proxy for ability-topay. Nonetheless, we believe that this will stimulate further studies on this. We also note that the criteria or elements used for judging quality at one moment may not be the same for the next, and that consequently client satisfaction and perception reflects only part of the quality of the entire health care process. This aspect should not be misunderstood or overestimated, nor should it replace the notion of quality care(29). 


\section{ACKNOWLEDGEMENTS}

We thank the anonymous reviewers for their comments. We are also grateful to the policy makers who facilitated the research.

\section{REFERENCES}

1. Akukwe, C. and Nowell, A.H. Essential strategies for achieving durable population-based maternal and child health services. J. Royal Soc. Hlth. 1999; 119:42-49.

2. CBN. Nigeria's development prospects: poverty assessment and alleviation study. Central Bank of Nigeria, Abuja, Nigeria. 1999.

3. Litvack, J.I. and Bodart, C. User fees plus quality equals improved access to health care: results of a field experiment in Cameroon. Soc. Sci. Med. 1993; 37:369-383.

4. Epstein, A. Sounding board: the outcomes movement, will it get us where we want to go? New Engl. J. Med. 1990; 323:266-269.

5. Blumenfeld, S.N. Quality assurance in transition. Рариа New Guinea Med. J. 1993; 36:81-89

6. Fisher, A.W. Patient's evaluation of outpatient medical care. J. Med. Educ. 1971; 46:238-244.

7. Barnett, B. Women's views influence choice. Network 1995; 16:14-18

8. Bruce, J. Fundamental Elements of the Quality of Care: A simple Frame Work. Studies in Family Planning 1990; 21: 61-91.

9. Jain, A. Fertility Reduction and the quality of family planning services. Studies in Family Planning. 1989; 20:1016.

10. Akin, J.S. and Hutchinson, P. Health-care facility choice and the phenomenon of by-passing. Hlth Policy Plann. 1999; 14:135-151.

11. Annis, S. Physical Access and utilisation of health services in rural Guatemala. Soc. Sci. Med. 1981; 15D:515 - 523.

12. Masatu, M.C., Klepp, K.I. and Kvale, G. Use of health services and reported satisfaction among primary school adolescents in Arusha, Tanzania. J. Adol. Hlth. 2001; 28:278-287.

13. Malata, M. First-time mothers' satisfaction with labour and childbirth information received: a Malawian perspective. Clin. Excellence in Nursing Practice. 2000; 4:83-89.

14. Whitworth, J., Pickering, H., Mulwanyi, F., et al. Deterrninants of attendance and patient satisfaction at eye clinics in south-western Uganda. Hlth Policy and Plann. 1999; 14:77-81.
15. Newman, R.D., Gloyd, S., Nyangezi, J.M., Machobo, F. and Muiser, J. Satisfaction with outpatient health care services in Manica Province, Mozambique. Hlth Policy Plann. 1998; 13:174-180.

16. Speizer, I.S. and Bollen, K.A. How well do perceptions of family planning service quality correspond to objective measures? Evidence from Tanzania. Stud Family Plann. 2000; 31:163-177.

17. Haddad, S., Fournier, P. and Potvin, L. Measuring lay people's perceptions of the quality of primary health care services in developing countries. Validation of a 20 -item scale. Intern. J. Quat. Hlth Care. 1998; 10:93-104.

18. De Geydnt W. Managing the quality of health care in developing countries.Washington, DC, The World Bank. 1995.

19. Msamanga, G. I. Urassa, D.P., and Mujinja, P.G.M. Equity of access to public, private not-for-profit and private for profit health facilities in two regions of Tanzania. Bamako Initiative Operations Research Programme Research Paper No. 4. 1993.

20. McPake, B, Hanson, K. and Mills, A. Community financing of health care in Africa. An evaluation of the Bamako Initiative. Soc. Sci. Med. 1993; 36:1383-1395.

21. Kloos, H. and Soula, G. Illness behavior in Addis Ababa and rural central Ethiopia. Social Sci. Med. 1987; 25:10031019.

22. Abel-Smith, B and Creese, A. (eds) Recurrent costs in the Health Sector-Problems and Policy Options in three Countries. Washington; USAID/WHO, 1989.

23. Kanji, N., Kilima P.M., and Munish G.M. Quality of Primary Health Care in Dar es Salaam. Dar es Salaam Urban Health Project. 1992; (Unpbl.)

24. Ahmed, A.M., Urassa, D.P. Gherardi. E., and Game, N. Y. Patients perception of public, voluntary and private health care services in dispensaries in rural areas of Tanzania. East Afr. Med. J. 1996; 73:31-34.

25. Calnan, M. Towards a conceptual framework for lay evaluation of health care. Social Sci. Med. 1988; 27; 927-933.

26. Fitzpatrick, R., Surveys of patient satisfaction: I. Important general considerations. Brit. Med. J. 1991; 302: 1129-1132.

27. Soucat, A. Gandaho, T. Levy-Bruhl, D. et al. Health seeking behavior and household health expenditures in Benin and Guinea; The Equity implications of the Bamako Initiative. Int. J. Health Planning Management. 1997; 12:S137-S163.

28. Egunjiobi, I. Factors influencing the utilization of hospitals: a case study of the northern part of Oyo State, Nigeria. Social Sci. Med. 1983; 17:585-589.

29. Brian W. Patient satisfaction: a valid concept? Social Sci. Med. 1994; 38:509-516. 